\title{
A história social atlântica de Stuart Schwartz
}

Entrevista $^{1}$

Faz um longo tempo que Stuart Schwartz descobriu o Brasil. Desde os anos 1960, consagrou-se como historiador do período colonial, estudioso da escravidão, da família escrava e da vida nos engenhos, e dos mecanismos do governo colonial como representante dos interesses do império luso. Mas, muito mais do que isso, atuou como articulador dos estudos brasileiros nos Estados Unidos, assumindo a formação de muitos historiadores brasileiros e norte-americanos. Essa múltipla atividade, que realiza hoje desde a Universidade de Yale, fez com que se tornasse uma figura incontornável do debate historiográfico, no Brasil, ao longo de mais de quatro décadas.

Stuart Schwartz concedeu a entrevista que se segue aos professores do Programa de Pós-graduação em História Social em junho de 2013. Ela se divide em três blocos. O primeiro deles parte do reconhecimento do grande manejo que Schwartz tem da produção acadêmica e da pesquisa em história do Brasil, consistindo, assim, numa discussão de ordem historiográfica. O segundo bloco é dedicado à polêmica travada, em 2002, com Carmen Bernand e Claude Lévi-Strauss, em torno da publicação da Cambridge history of native peoples of the Americas, coordenada por Stuart Schwartz e Frank Salomon. Se retornamos, pouco mais de dez anos depois, a essa discussão, é por seu caráter revelador de posicionamentos intelectuais e institucionais e pelos efeitos que produziu, cuja repercussão foi bastante curta no Brasil. O terceiro bloco trata de sua agenda de estudos atual, voltada para a confecção de uma história social dos furacôes no Caribe, do século XVI ao XIX.

Andrea Daher: Stuart Schwartz, você foi considerado um brasilianista, desde os anos 60. No entanto, o sentido do termo parece não ser o mesmo ao longo desses anos. Perguntaria, então, na abertura desta entrevista: o que significa hoje ser brasilianista? Não teria havido, mais do que uma mudança, um esvaziamento do significado do termo? De que modo você vê sua adequação ao qualificativo?

Stuart Schwartz: Brasilianista! Eu me lembro muito bem que, quando iniciei meus estudos sobre o Brasil, um número da revista Veja, que apareceu por volta de 1963, estampava na capa: "Grandes figuras do Brasil”. Tiradentes, Rui Barbosa, D. Pedro II apareciam

\footnotetext{
${ }^{1}$ A revisão, a edição final e a apresentação desta entrevista foram feitas por Andrea Daher, professora de história da Universidade Federal do Rio de Janeiro.
} 
com aqueles balóes de histórias em quadrinhos, mas suas falas estavam em inglês, como por exemplo, o "Independency or death" de D. Pedro I. E todo o artigo era sobre os brasilianistas e como eles estavam roubando a história do Brasil. Houve um debate naquele momento e alguns historiadores brasileiros se posicionaram de um lado, outros de outro; era um momento interessante. Mas a ideologia "brasilianista" foi um produto da Guerra Fria porque, durante esse período, depois de 1960, era evidente nos Estados Unidos que as relaçôes com a América Latina não estavam muito "de pé". Então, o governo norte-americano começou a investir na preparação de especialistas que tivessem algum conhecimento da vida, da cultura e da história da América Latina. Havia muitas pessoas que falavam espanhol, mas poucas que falavam português. $\mathrm{O}$ estudo do português passou a ser promovido pelo governo norte-americano - tratava-se de um incentivo porque o português era considerado uma língua importante para a posição dos Estados Unidos nas suas relaçôes mundiais. E o resultado foi o surgimento, nas universidades, de um novo interesse pelo Brasil.

Entrei na pós-graduação em 1962 com a intenção de estudar o Japão, pois havia, naquele momento, uma preparação, em nível de graduação, em estudos asiáticos. Eu já havia tido a experiência de morar por um tempo no México, falava um pouco de espanhol e havia estudado na Universidade Nacional Autônoma do México. Portanto, me interessava também pela América Latina. Mas quando cheguei ao doutorado, em Columbia, havia vários jovens estudantes interessados no Brasil. Na minha turma estavam Ralph Della Cava, que escreveu um livro sobre o padre Cícero; Joseph Love, que publicou um livro sobre São Paulo; havia também Kenneth Maxwell, Robert Levine e Peter Eisenberg, que veio para o Brasil e foi professor em Campinas. Michael Hall ainda é professor em Campinas. E por que o interesse pelo Brasil? Uma vez Thomas Skidmore disse: "Brasilianistas, somos todos afilhados de Fidel”. Porque foi com a Revolução Cubana que o governo norte-americano se interessou em investir em estudos sobre a América Latina que não existiam antes. É nesse sentido que somos todos "afilhados de Fidel". Mas, se o governo norte-americano esperava encontrar especialistas para apoiar a sua política na América Latina, o resultado foi exatamente o contrário. As críticas à política do governo que vêm dessa geraçáo não eram aquilo que ele esperava.

E também, desde o início, houve problema quanto à definição de "brasilianista". Peter Eisenberg - que, como disse, é formado nos Estados Unidos e passou toda sua vida como professor no Brasil - é brasilianista? Que tipo de brasilianista é? E os vários professores brasileiros, como Manuela Carneiro da Cunha, que foi para Chicago e passou sua carreira acadêmica lá, como podemos defini-la? Parece-me que há uma troca — algumas pessoas falavam no "rapto dos Sabinos", porque os brasilianistas chegaram aqui, alguns voltaram aos Estados Unidos e alguns se casaram e ficaram no Brasil. Então, existe uma confusão nesse sentido, pois há muitos historiadores formados nos Estados Unidos que trabalharam no Brasil. Há pessoas como Ana Lugão Rios, brasileira, formada nos Estados Unidos; ou João 
José Reis, outro orientando meu, brasileiro, também formado nos Estados Unidos; John Monteiro é outro bom exemplo.

O termo "brasilianista" talvez tivesse, de fato, um sentido diferente nos anos 60 , quando os programas de pós-graduação no Brasil ainda não eram muito desenvolvidos. Com eles, mais tarde, foi introduzida uma preparação profissional, outra maneira de pensar e certa liberdade de acesso à documentação, nesse período muito difícil que foi o início da ditadura militar. Eu me lembro de um americano que dirigiu um projeto dentro do Arquivo Nacional, no Brasil. E nós nem pensávamos em aceitar uma posição desta! Deixar um brasileiro de lado para ter um americano dirigindo um projeto dentro do Arquivo Nacional era uma coisa feia! Isso foi um momento. E esse momento passou. É nesse sentido que penso que o termo "brasilianista" hoje não tem o mesmo significado que tinha naquela época.

Mas na história do Brasil sempre houve estrangeiros observadores da realidade, desde que os portos se abriram, em 1810. Não se pode pensar na história do Brasil do início do século XIX sem o livro de John Armitage, por exemplo. E quantos mais? Há ainda os franceses. No século XX, houve Pierre Verger. Não se pode pensar a historiografia da Bahia sem Pierre Verger. Braudel esteve no Brasil também. Quanto a Lévi-Strauss, Tristes tropiques foi um livro da minha formaçáo, um livro que me atraiu para o Brasil.

Então, acho que se pode falar de dois olhares: o olhar de dentro, do brasileiro; e o olhar de fora, do estrangeiro. Eu lembro muito bem quando era estudante de pós-graduação e li uma história da Inglaterra de meados do século XIX escrita por um francês, uma história muito importante, cujo autor não me lembro. Ele conta na introdução do livro que, através de uma janela da British Library, onde costumava trabalhar, avistou a bandeira inglesa e pensou que qualquer menino, nas ruas de Londres, entendia as coisas melhor do que ele, mesmo depois de tantos anos de estudo. Porque esse menino nascera dentro dessa cultura que ele fazia tanto esforço para compreender, uma cultura que não era a dele. Eu sempre pensei que essa era uma observaçáo muito boa, pois qualquer um de nós, historiadores, que tratamos de estudar uma cultura que não é a nossa, temos o mesmo problema. Como se aproximar para entender essa cultura? Mas o nosso objetivo é sempre o de traduzir aquela cultura para a nossa. Assim, americanos, espanhóis, ingleses têm a possibilidade de conhecer o Brasil e de levar esse conhecimento para a sua própria cultura. Mas eu sempre sonhava também, quando era estudante e fazia minhas primeiras pesquisas aqui, em chegar bastante perto dessa cultura e fazer algo que fosse do interesse dos brasileiros: este foi um sonho meu. Espero que, durante esses quarenta e tantos anos, esse meu sonho tenha se realizado.

Monica Grin: Quando você diz que o seu objetivo primeiro era compreender, era estudar o Brasil para comunicar esse Brasil no contexto norte-americano, isso talvez explique o seu interesse muito focado no tema da escravidão. 
Stuart Schwartz: Sim. E nesse momento especialmente. Nos anos 60 havia um movimento em prol dos direitos humanos, civis. Então essas questóes de racismo, de preconceito racial, estavam diante da minha geração. Nesse sentido, havia muito interesse na escravidão porque, nesse momento também, muitos livros importantes, com análises comparativas, foram publicados. E o Brasil era sempre o grande contraponto dessas análises. Então, por isso foi natural que a minha geração se interessasse tanto pelo tema da escravidão.

José Augusto PÁdua: Gostaria de perguntar sobre outro aspecto desta mesma questão. Conheço norte-americanos formados como pesquisadores do Brasil que, durante o período da hiperinflação, da crise econômica brasileira, mudaram de tema e foram estudar o México, o Chile, porque se sentiam sem apoio na academia norte-americana, por razóes relacionadas à política, à geoeconomia e à geopolítica internacional. Então, a minha pergunta é a seguinte: para você que viveu essa experiência de transpor fronteiras, como é essa relação entre o interesse historiográfico de pesquisa e as questóes mais gerais da geoeconomia e da geopolítica que acabam por influenciar essa decisão?

Stuart Schwartz: Não sei exatamente como responder, mas acho que é importante vocês entenderem que todos os americanos formados em história do Brasil são parte de um programa de estudos latino-americanos. Para eles, o Brasil é parte da América Latina. Para vocês, o estudo do Brasil é um estudo nacional. Um brasilianista é formado, primeiro, em estudos de América Latina, e o Brasil é a sua especialidade, ou seja, uma parte de sua formação. Eu acho que isso dá uma visão um pouco diferente ao brasilianista.

Em relação à outra parte da pergunta sobre a diferença entre a formação acadêmica e a influência da situação política e econômica, isso é mais difícil de saber. Acho que isso depende muito da origem do acadêmico e também das condiçóes de sua universidade na sua formação. Não tenho uma boa resposta para isso, mas é uma boa pergunta.

Lise Sedrez: Em 2010, assisti a um evento que celebrava os seus quarenta anos de carreira, no encontro da American Historical Association em San Diego, e algo que me impressionou na época foi a quantidade de pessoas que você orientou. Não é só a quantidade de livros publicados que impressiona, mas também a quantidade de estudantes orientados por você. Ao mesmo tempo, você acompanhou um momento crítico da produção historiográfica brasileira e da transformação do ensino superior no Brasil. Nosso colega José Murilo de Carvalho declarou algumas vezes, em artigos de jornais, que ele acredita que, neste momento de maturidade dos programas de pós-graduação no Brasil, não existe mais muito sentido em enviar estudantes para fazer doutorados em história do Brasil nos Estados Unidos - embora ele sublinhe a importância do intercâmbio e da chamada "bolsa sanduíche". Nessa perspectiva, como você vê essa mudança no perfil do estudante brasileiro que estuda nos Estados 
Unidos? Para você, ainda tem sentido fazer doutorados completos nos Estados Unidos sobre história do Brasil?

Stuart Schwartz: Através dos anos tive vários estudantes brasileiros em nível de mestrado e de doutorado. Mas, nos últimos dez anos, tive muitos orientandos brasileiros com "bolsas sanduíche" (e também de pós-doutorado). Acho isso muito bom, porque eles são formados no Brasil e passam um ano, mais ou menos, nos Estados Unidos, com os nossos recursos de bibliotecas. E é muito bom também para os meus estudantes americanos, para que eles possam ter uma experiência intelectual ao lado de colegas brasileiros (eu sempre aceito esses bolsistas porque também é muito importante para a formação dos meus estudantes de lá). Mas acho que, sim, agora existem programas de pós-graduação de alto nível no Rio de Janeiro, em São Paulo, na Bahia e em universidades por todo o Brasil. É outro Brasil, outro momento educacional no Brasil. De todo modo, sempre houve pessoas formadas nos Estados Unidos, na França ou na Inglaterra entre nós, o que enriquece os recursos intelectuais do país.

Andrea Daher: Para fechar esse bloco, consideremos, por um lado, a sua grande experiência como historiador; e, por outro, o fato de que essa figura do "brasilianista" não é mais operatória na configuração político-disciplinar contemporânea. A partir daí, a pergunta é: como você vê o lugar da sua contribuição para a historiografia brasileira de hoje? Onde ela encontra eco e quais seriam as suas interlocuçóes mais fortes?

STUart Schwartz: Tenho publicadas três monografias relacionadas à história do Brasil e alguns outros livros. A primeira foi Burocracia e sociedade no Brasil colonial, publicada pela Editora Perspectiva (agora saiu uma nova edição pela Companhia das Letras). ${ }^{2}$ Este é um livro sobre o Tribunal da Relação da Bahia, o primeiro Tribunal Superior do país. E o título era para mostrar como os desembargadores, representantes do império português naquele momento, quando chegaram ao Brasil, se casaram, tiveram sócios de negócios e serviram, de fato, como agentes dos interesses brasileiros para o império. Esse livro teve um grande impacto, e foi muito citado em outros livros sobre a Relação (Arno Wehling fez um livro sobre a Relação do Rio de Janeiro, utilizando o meu como modelo). ${ }^{3}$ Mas o interessante é que, nos últimos anos, esse debate entre historiadores do Rio de Janeiro e de Sáo Paulo sobre a natureza do governo como representação dos interesses do império voltou. E eu acho, sem tomar partido na discussão, que ele é uma extensão exatamente do argumento que eu estava tratando de resolver naquele momento, nos anos 60 e início dos 70 . Estou muito contente de

\footnotetext{
2 SCHWARTZ, Stuart B. Burocracia e sociedade no Brasil colonial: o Tribunal Superior da Bahia e seus desembargadores, 1609-1751. São Paulo: Companhia das Letras, 2011.

${ }^{3}$ WEHLING, Arno; WEHLING, Maria José. Direito e justiça no Brasil colonial: o Tribunal da Relação do Rio de Janeiro (1751-1808). Rio de Janeiro: Renovar, 2004.
} 
ver como esta voltou a ser uma pergunta interessante. E, repito, não estou tomando partido no debate, mas acho que é uma questão importante e que é um tipo de espinha dorsal para a história do Brasil: o governo representava ou não os interesses locais? Se tomarmos o livro do jurista Raymundo Faoro, Os donos do poder, ${ }^{4}$ a questão é exatamente esta. Para Faoro, o governo era sempre algo separado da sociedade. E o meu livro é uma tentativa de mostrar que o governo sempre representa alguns interesses — não todos, mas alguns —, pois não está fora da sociedade, ele é parte dela, é uma arma dentro dela. Bem, esse é o meu primeiro livro.

Levei doze anos preparando o segundo livro, Segredos internos. ${ }^{5}$ Era uma tentativa de pensar a zona açucareira e a sociedade açucareira e, com isso, de retomar Gilberto Freyre sem Gilberto Freyre. E comecei com a ideia de contestá-lo. Mas essa foi uma ideia de juventude que deixei de lado, porque Freyre entende a cultura brasileira muito melhor do que Stuart Schwartz. Eu me concentrei, então, na documentação. Como era montar um engenho? Como era viver, morar, nesse mundo dos engenhos, para os escravos e para os senhores, mas também para os artesãos, os homens livres e os lavradores de cana? Ou seja, para todos aqueles que existiam naquela sociedade, mas que não aparecem em Gilberto Freyre, porque Casa-grande \& senzala é um livro sobre senhores e escravos, e o resto da sociedade desaparece.

Publiquei também uma série de artigos em torno desse livro. Alguns apareceram em Escravos, roceiros e rebeldes, ${ }^{7}$ que é uma coletânea de ensaios e de artigos que vão nesse sentido. Também fiz muitos estudos sobre a escravidão, sobre a família escrava, sobre compadrio etc. Acho que meu estudo sobre compadrio é o primeiro estudo histórico feito no Brasil sobre esse tema. Agora existem muitos, sobre outras regióes, mas naquele momento havia sido o primeiro. Fiz estudos sobre alforria, utilizando as cartas de alforria. Esse foi um projeto que montei com Kátia de Queiroz Mattoso e com um jovem americano chamado Arnold Kessler que nunca acabou seu doutorado, mas trabalhou na Bahia e fez parte do nosso projeto. Cada um de nós trabalhava com uma cronologia específica: Kátia ficou responsável pelo estudo do século XIX, eu pelos séculos XVII e XVIII, e Kessler de 1850 até o fim da escravidão. Ele não terminou o trabalho, mas Kátia e eu publicamos nossas partes. Esses foram alguns dos primeiros estudos utilizando cartas de alforria de uma forma quantitativa. Sempre penso que esta foi uma boa contribuição.

Também foi uma boa contribuição a publicação que fiz de um tratado de paz que escravos fugidos estabeleceram para voltar a serem escravos. Um grupo de escravos fugidos do Engenho de Santana, em Ilhéus, onde a vida deles era muito difícil, preparou esse tratado que continha as condiçóes a partir das quais eles voltariam a ser escravos. Uma coisa impen-

\footnotetext{
${ }^{4}$ FAORO, Raymundo. Os donos do poder: formação do patronato político brasileiro. 3. ed. São Paulo: Globo, 2001 [1958].

5 SCHWARTZ, Stuart B. Segredos internos: engenhos e escravos na sociedade colonial 1550-1835. Sáo Paulo: Companhia das Letras, 1988.

${ }^{6}$ FREYRE, Gilberto. Casa-grande \& senzala. Rio de Janeiro: Record, 2000 [1933].

${ }^{7}$ SCHWARTZ, Stuart B. Escravos, roceiros e rebeldes. Bauru: Edusc, 2001.
} 
sável! Eu descobri esse documento quando estava pesquisando sobre o açúcar, no Arquivo Público da Bahia, numa miscelânea chamada "Cartas ao Governo". Nela, havia uma carta do juiz da Penitenciária da Bahia ao desembargador ouvidor dizendo que eles tinham um preso há doze anos que queria ter o seu processo finalizado, e como apêndice à carta estava o tratado. Lembro-me que, ao ler este documento, me levantei e comecei a sambar em volta da mesa. Eu estava tão emocionado! Nesse momento, uma arquivista, que vinha da regiáo de Santo Amaro, a região do açúcar, me perguntou: "O que você encontrou?". Então, mostrei o documento; ela o leu e começou a chorar. Ela entendia muito bem o que aquilo significava. Então, publiquei esse documento e levei uma semana para fazer um pequeno artigo sobre ele, que foi lido por muitos. Jacob Gorender escreveu todo um livro contra o artigo. E eu logo pensei que havia demorado dez anos preparando o livro sobre burocracia e sociedade, e que talvez cinco pessoas o tivessem lido, enquanto o documento, que me levou apenas uma semana de preparação, me deixou famoso. Eu era "o homem do documento"!

Bem, depois disso passei para o estudo da tolerância religiosa. Esse foi um estudo mais amplo, a partir da minha formação sobre a América espanhola e sobre a Espanha. E foi com a ajuda de Fernando Bouza que terminei esse livro, que também tem um capítulo específico sobre o Brasil (uma parte do livro, sobre o século XVIII, também trata do Brasil, mas o livro é principalmente sobre o mundo ibérico). ${ }^{8}$ Depois passei para o meu novo estudo sobre os furacôes que é uma história ambiental, social e política. Num certo sentido, com esse novo estudo não deixo de lado os meus antigos interesses porque sempre fui um historiador da história social - esta é a minha própria definição. Mas talvez agora eu dê mais atenção à cultura, enquanto nos anos 70 e 80 eu estava mais envolvido com a economia e com os métodos da história econômica.

Sou muito eclético em termos de metodologia. Acho que a metodologia depende da pergunta que se está fazendo: para um determinado tipo de pergunta você precisa do método quantitativo, para outras questôes você precisa de outros métodos. Eu não sou "cativo" da metodologia, estou buscando os métodos que mais me facilitem responder as perguntas que me interessam.

Andrea Daher: No segundo bloco desta entrevista, passamos para a polêmica travada, no final de 2002 e começo de 2003 — pouco conhecida no Brasil —, em torno da publicação da Cambridge history of native peoples of the Americas," dirigida então por você e por Frank Salomon. A publicação causou uma reação muito forte na França, onde um volume da revista Annales foi dedicado a resenhas críticas de historiadores, como Luís Felipe de

\footnotetext{
${ }^{8}$ SCHWARTZ, Stuart. B. Cada um na sua lei: tolerância religiosa e salvação no mundo atlântico ibérico. São Paulo; Bauru: Companhia das Letras; Edusc, 2009.

${ }^{9}$ SALOMON, Frank; SCHWARTZ, Stuart B. (Org.). The Cambridge history of the native peoples of the Americas III: South America, Parts 1 \& 2. Cambridge: Cambridge University Press, 1999.
} 
Alencastro, ${ }^{10}$ e antropólogos, como Carmen Bernand. ${ }^{11}$ Paralelamente, na revista L'Homme, Claude Lévi-Strauss também publicou uma resenha particularmente severa quanto ao direcionamento que foi dado a essa obra coletiva. ${ }^{12}$ Então, você e Salomon se posicionaram conjuntamente em relação a essas críticas, em particular à de Carmen Bernand que identifica na obra quatro sintomas de uma espécie de "vírus pós-moderno". Segundo ela, "hostilidade à assimilação, celebração da cultura da diferença, inflação da alteridade e radicalização dos conflitos" seriam as características das contribuições do volume. A resposta, sua e de Salomon, desde o título "Um americano (imaginário) em Paris", ${ }^{13}$ sugere que esse americano pós-moderno fosse uma construção francesa, uma alteridade americana ultrarrelativista, multiculturalista, totalmente radicalizada.

Por sua vez, na crítica de Lévi-Strauss, a acusação segue no sentido de um revisionismo. E a sua resposta aponta a total estranheza de uma acusação como tal dirigida a autores cujos nomes são Schwartz e Salomon. Mas trata-se, sobretudo, para Lévi-Strauss, de um revisionismo do caráter violento da colonização, de uma espécie de sobrevalorização da nova história indígena em detrimento do caráter propriamente genocida e violento da Conquista.

Que consequências podem ser tiradas deste debate, travado num momento pós-estruturalista da antropologia? Quais são as consequências heurísticas para a história e a antropologia dos povos indígenas, passados agora dez anos?

Stuart Schwartz: As consequências são difíceis de saber. Todo esse debate e a dificuldade de negociar a nossa resposta com a revista Annales nos custaram muito tempo e muito trabalho. E algumas das acusaçóes feitas nas resenhas eram muito difíceis de entendermos. Por um tempo, carreguei comigo um exemplar da resenha que Carmen Bernand escreveu nos chamando de "pós-modernos". E eu andava com isso para mostrar aos meus estudantes, porque para eles eu estava muito longe de ser um pós-moderno. Achei uma coisa muito estranha. Penso que, no fundo, houve na França, exatamente nesses anos, no início do século XXI, uma crise nas ciências humanas, especialmente na antropologia, que se pode chamar de pós-estruturalismo. Porque a academia francesa era muito influenciada pelo estruturalismo, especialmente a antropologia, por Lévi-Strauss. E quando aquela interpretação estruturalista perdeu território, a academia francesa não tinha uma ideia clara de para onde iria. $\mathrm{O}$ mesmo podemos dizer sobre a revista Annales que durante um período tinha uma linha e que agora tem várias linhas. Um amigo francês antropólogo me disse, na época, que o pro-

${ }^{10}$ ALENCASTRO, Luiz Felipe de. L'histoire des amérindiens au Brésil. Annales HSS, v. 57, n. 5, p. 13231335, 2002.

${ }^{11}$ BERNAND, Carmen. L'américanisme à l'heure du multiculturalisme. Projets, limites, perspectives. Annales HSS, v. 57, n. 5, p. 1293-1310, 2002.

${ }^{12}$ LÉVI-STRAUSS, Claude. SALOMON, Frank; SCHWARTZ, Stuart B., eds., The Cambridge history of the native peoples of the Americas. L'Homme, p. 158-159, avr./sept. 2001.

${ }^{13}$ SALOMON, Frank; SCHWARTZ, Stuart B. Un américain (imaginaire) à Paris. Réponse à Carmen Bernand. Annales HSS, n. 2, p. 499-512, mars/avr. 2003. 
blema era, de fato, que a antropologia francesa não sabia para onde ia, mas que os franceses estavam seguros de que os americanos não chegariam lá primeiro.

Quanto à reação dos antropólogos franceses ao nosso volume, acho que houve um pouco de nacionalismo. Temos que situar isso num contexto maior, porque no mesmo número da revista Annales no qual apareceu a resenha de Carmen Bernand apareceram também outras resenhas, como a de Serge Gruzinski, sobre outros volumes da Cambridge history. Todas elas muito críticas! E todas a partir de uma mesma perspectiva, o que indicava que o problema não era simplesmente o nosso volume, mas uma concepção da vida intelectual norte-americana vista pelos franceses. E por isso o título da nossa resposta é "Um americano (imaginário) em Paris", baseado no título daquele filme famoso com Gene Kelly, Um americano em Paris.

Bem, primeiro, em relação à crítica de Lévi-Strauss, perguntamos: é possível fazer uma história dos índios que não comece em 1492? E mesmo, a partir de 1492, o índio só tem história em confronto com o europeu? Acho que Lévi-Strauss queria que editássemos um volume chamado "A triste Cambridge history dos povos indígenas das Américas". Porque para ele trata-se disso! Ele não considera, por exemplo, que na Bolívia, agora, há um presidente de origem indígena e movimentos políticos indígenas. No Chile e na Guatemala também. Então, o nosso objetivo era fazer do índio um agente de sua própria história. Isso não nega a existência da violência da Conquista ou do genocídio nas conquistas; não nega a escravidão; não nega o fracasso da integração dos índios dentro das repúblicas nacionais no século XIX. Não nega nada disso! Trata-se simplesmente de dizer que alguns índios também eram agentes da história, porque se não fizermos isso, não é possível explicar como os índios, em vários pontos da América, chegaram a ser caciques ou chegaram a exercer determinada influência. Como responderíamos a questóes como a da rebelião de Tupac Amaru? Então, o nosso objetivo era fazer do índio um ator de sua própria história. Para Lévi-Strauss, desde seu curto período de estudo de campo no Brasil, qualquer integração de culturas era uma perda. A cultura que importa era a cultura original e qualquer mudança dessa cultura original é uma perda, é triste. E Tristes trópicos é um exemplo disso.

A crítica de Carmen Bernand também dizia que a historiografia francesa não era citada o suficiente. Mas me parece que ela não entendeu que a Cambridge history não tem notas de rodapé e, sim, ensaios bibliográficos. E cada capítulo tem um ensaio bibliográfico (acho que ela não leu os ensaios bibliográficos quando fez a resenha). E quando tratamos de demonstrar isso na nossa resposta à resenha, não nos deixaram publicar esse parágrafo. Lembro que Nathan Wachtel é citado quinze vezes, e Lévi-Strauss dezenove vezes. Isso confirma que ela não tinha lido os ensaios bibliográficos. Seria estranho, por exemplo, fazer uma classificação da origem dos autores que usamos: tantos suíços, tantos canadenses, tantos americanos, como se essa fosse uma chave para entender a escrita. Mas, na base de tudo, é verdade que há uma diferença no modo de se pensar uma nova sociedade de múltiplas culturas, nos Estados Unidos e na França. Penso naquela lei que pró́be o uso do véu islâmico na França, 
por exemplo, que não existe nos Estados Unidos. Essa é a linha francesa, uma linha de integração dentro da república. É uma maneira de se pensar sobre isso. Nos Estados Unidos há pessoas que pensam assim, mas isso não se tornou lei federal, o que demonstra que há uma diferença. Acho que Lévi-Strauss e Bernand estavam projetando sobre os nossos autores esta ideia da cultura americana e sua maneira de integrar outras culturas. Alguns deles eram franceses - foram, inclusive, os únicos que receberam bons comentários nas resenhas. Os únicos! Alguns eram latino-americanos, do Peru e do Brasil, como Manuela Carneiro da Cunha. Então, acho que houve uma reação nacionalista, mas isso gerou um questionamento muito importante em torno de como nós, historiadores, podemos fazer uma história dos vencidos de modo que eles tenham um papel em sua própria história. Não se pode dizer, nesse sentido, que o índio não era um agente da história. Houve períodos de assimilação, períodos de resistência, mas o índio faz parte de sua própria história. A mesma coisa seria dizer que o Holocausto não aconteceu na Europa.

Andrea Daher: A obra de Nathan Wachtel é um exemplo de trabalho que reúne, metodologicamente, postura antropológica e procedimento historiográfico, como exemplo irrecusável de uma história indígena nesses moldes.

Stuart Schwartz: Sim. Wachtel se sentiu muito incomodado com o nosso debate. Ele achou que era excessiva a crítica e que alguns dos pontos não estavam corretos. Mas o pior não foi a crítica, foi que a revista Annales não queria deixar que fizéssemos a resposta como queríamos e, ao final, eles publicaram a nossa resposta depois de muita negociação. Publicaram nossa resposta com uma página de abertura, ou seja, uma intervenção editorial defendendo as resenhas diante das respostas dos autores. Isso não é comum entre as revistas acadêmicas de história.

Monica Grin: O seu livro sobre tolerância também foi objeto de críticas dessa natureza por reforçar, de alguma maneira, uma ideia multiculturalista em relação aos grupos estudados.

Stuart Schwartz: Não sei. Mas eu sei que o livro nunca teve uma resenha publicada pela revista Annales (teve outras resenhas e ganhou vários prêmios). Isso me surpreendeu porque tenho vários amigos na École des hautes études en sciences sociales, e mandei vários exemplares do livro, mas nunca chegaram a fazer uma resenha. Meus amigos gostaram: Nathan Wachtel gostou muito e Jean-Frédéric Schaub também (um amigo de muitos anos, que publicou um livro dedicado a mim). Já fui professor visitante na École e não tenho problema nenhum com a academia francesa. Mas o interessante é que este livro nunca recebeu uma resenha que tivesse sido publicada na revista Annales. 
Andrea Daher: Passemos para o terceiro bloco de perguntas sobre a sua agenda futura de pesquisas, voltada para a história dos desastres naturais, o caso dos furacôes no Caribe. Qual é o sentido de um projeto como este, pensado como uma história social, de longa duração, que do ponto de vista teórico deve enfrentar as questóes hoje colocadas, particularmente por vertentes da história ambiental e da antropologia?

StUART Schwartz: Este estudo começou realmente quando eu estava trabalhando sobre o açúcar na Bahia. Nesse período, eu estava lendo muita coisa sobre escravidão, não só no Brasil, mas nos Estados Unidos e no Caribe. E com essa leitura, me familiarizei com a historiografia do Caribe. E o Caribe tem o que podemos chamar de metanarrativa da escravidáo, das plantations, das grandes propriedades, de guerras imperiais - essa regiáo era o centro das guerras entre franceses, holandeses, espanhóis, ingleses etc. Mais tarde, no século XIX, as narrativas se voltaram para a imigração, depois da queda da economia do Caribe. Há mais porto-riquenhos que moram em Nova York do que em Porto Rico. Então, eu queria fazer alguma coisa sobre o Caribe, mas não mais um livro sobre escravidão (depois de quinze anos trabalhando sobre isso). Penso que já disse o que tinha de dizer sobre esse assunto.

Então, no verão, eu estava relendo $O$ Mediterrâneo, de Braudel ${ }^{14}$ - o que sempre me dá um certo prazer - e notei que, para ele, um fator muito importante era justamente o clima, o ambiente: como as montanhas influenciavam a vida, o mar, as ilhas? Como tudo isso influencia a vida e como isso forjou a cultura do mediterrâneo e os hábitos em relação ao vinho, ao pão, ao cultivo da azeitona etc.? Então, pensei: e o Caribe? O Caribe é um "tipo de Mediterrâneo", pois é um mundo marcado por sua posição geográfica. E uma característica do Caribe é justamente o furacão. Eu comecei a pensar num mundo atlântico — que, afinal, é o que me interessa - , num mundo centrado em Barbados.

Imaginemos um mapa em que o centro não é Jerusalém e, sim, Barbados. Entre 4 e 5 mil quilômetros a oeste está Dakar, na costa da África. A 4 mil e poucos quilômetros a oeste está a Cidade do México. Quatro mil quilômetros ao norte, Washington e a baía do Chesapeake, que era o centro da zona escravista e de fumo nos séculos passados. Mais ou menos a 4 mil quilômetros ao sul, está a baía de Guanabara, no Rio de Janeiro. Mas se colocarmos o compasso em Barbados, no mapa, e fizermos esse circuito, teremos o Atlântico, que, como disse, é o que me interessa.

O furacão é um fenômeno exatamente dessa zona, da linha do Equador para o norte. Comecei então a pensar numa história ambiental sobre os furacóes. Descobri que o furacão é um fenômeno limitado no calendário anual, ou seja, só acontece entre os meses de junho a novembro, quando as águas do Atlântico são mais quentes e produzem as condiçóes para gerá-los. O primeiro aspecto que me interessou foi que, quando os europeus chegaram,

\footnotetext{
${ }^{14}$ BRAUDEL, Fernand. O Mediterrâneo e o mundo mediterrânico na época de Filipe II. São Paulo: Livraria
} Martins Fontes, 1984. 2 v. 
encontraram um fenômeno natural que não existia na Europa e não era conhecido. E a primeira coisa que os europeus do século XVI queriam, quando encontravam um fenômeno da natureza, era buscar uma explicação para ele. Dessa forma, recorreram imediatamente às obras clássicas de Ptolomeu, de Aristóteles. Assim, os espanhóis tiveram que observar um fenômeno para o qual não havia explicação nem na Bíblia, nem nas obras clássicas. E alguns marinheiros, visitantes e cronistas começaram a acumular informaçóes sobre isso e falar com os índios para ver o que sabiam sobre esse fenômeno.

Já no século XVI houve um início de entendimento desse fenômeno como natural, e não como fenômeno unicamente divino. Porque sempre os padres diziam que os furacóes eram uma resposta dos céus originada pelos pecados humanos na Terra. Mas, naquele momento, havia também espanhóis laicos que estudavam e se questionavam: "Se Deus envia um castigo através do furacão, por que ele vem somente em junho? Se a explicação são os nossos pecados, por que o furacão passou sobre nossa ilha e depois sobre outras? Os pecados são iguais?”. Portanto, havia dúvidas sobre a origem divina do fenômeno.

Depois, no século XVII, chegaram à região os ingleses e os franceses que leram os textos dos espanhóis e falaram com os índios. Os africanos também tinham um entendimento dos desastres, das enchentes, e construíram, junto com os outros, um conhecimento que podemos chamar de criollo. E cada ilha tem uma variação desse conhecimento criollo. Em Porto Rico, por exemplo, se havia uma boa colheita de abacate, era um sinal de que seria uma temporada dura de furacóes.

No século XVIII, com o iluminismo, as coisas curiosas foram mudando. No mundo espanhol, no Peru e no Chile, depois dos terremotos ainda se produzia uma literatura, constituída de sermóes e de outros gêneros, voltada para os castigos divinos. Isso não acontecia no caso dos vulcóes. Havia uma diferença, portanto, na forma em que vulcóes e terremotos eram vistos pelas sociedades. Talvez esse fosse o início da necessidade de uma observação mais científica, no século XVIII, com maior interesse nos fenômenos da natureza que tinham uma origem na astrologia e na astronomia (mais baseados na observação). No início do século XVIII foram criados instrumentos, como o barômetro e o termômetro, e observaçôes foram feitas em meados do século, tais como o estabelecimento de mediçóes pluviométricas ou da força do vento. Isso tudo parte do movimento iluminista e do liberalismo: no Caribe, aqueles que se interessavam por isso eram os que mais apoiavam a escravidão. Todos os grandes cronistas do Caribe, os grandes historiadores da Jamaica, por exemplo - a Jamaica tem excelentes historiadores no século XVIII — , são defensores da escravidão. Um pouco como o bispo do Brasil, Azeredo Coutinho, que era um exemplo do iluminismo português e um grande defensor do comércio de escravos. Mais tarde, no Caribe de meados do século XIX, era muito difícil também separar esse tipo de percepção da natureza das ideias de racismo científico. 
A história geral dos desastres naturais é muito interessante. Então, se nos séculos XVI e XVII é o pecado do homem que causa o desastre natural, que provoca Deus a dar uma lição, em meados do século XVIII e, especialmente no XIX, surge um entendimento das leis da natureza, no sentido de que é possível que Deus tenha sido responsável pela criação do mundo, mas as leis da natureza possuem suas próprias regras. E, ao chegarmos ao final do século XX e no século XXI, com a ideia de meio ambiente e de que a ação do homem está destruindo a natureza, a culpa é colocada, mais uma vez, no homem.

Ao longo de quinhentos anos de história dos desastres naturais, partimos da responsabilidade humana, pelo pecado, para a responsabilidade da natureza e, agora, de novo, os homens assumem a responsabilidade. Acho que a história do ambiente sempre tem, por detrás, uma história do entendimento humano e uma história da ciência que faz parte das mentalidades. $\mathrm{O}$ meu projeto está mais concentrado em entender como as sociedades e os governos reagiram diante dos desastres naturais, porque nos séculos XVI e XVII eles não eram responsabilidade do governo. Talvez fossem responsabilidade da Igreja, da sociedade, mas o governo pouco se responsabilizou. Isso só se deu no século XVIII, ao mesmo tempo na França e na Inglaterra e, mais tarde, na Holanda. Os espanhóis assumiram essa responsabilidade mais cedo, no século XVI, mas por outras razóes. Então, é um projeto de estudo sobre quinhentos anos de história que trata de entender a relaçáo entre desastres naturais, políticas de governo, responsabilidade e contexto social.

Lise SEDREZ: Parece-me que, no seu trabalho, o papel das sociedades e dos governos tem grande importância, e que o conceito de "império", em especial, é central para este projeto. Ou seja, vemos franceses e ingleses compartilhando este mesmo espaço que é o Grande Caribe. Mas, embora os furacôes sejam importantes nesta regiâo, há também terremotos, enchentes, tsunamis, um pouco de tudo. Ao mesmo tempo, na pesquisa que desenvolvemos sobre enchentes, estamos chegando à conclusão de que esses grandes modelos de nação ou de império não dão conta completamente do objeto porque "places matter", como dizia John Opie. Ou seja, os lugares específicos importam e fazem diferença em história ambiental, e os grupos sociais dentro daquelas sociedades "fazem diferença", ou seja, também experimentam de forma diferente o desastre. Eu sei que você náo quer escrever outro texto sobre escravidão, mas como você vai trabalhar com a forma como estes diferentes grupos sociais vivem os desastres? Por exemplo, como os escravos vivem o desastre? E como é a experiência de outros grupos, como os senhores de escravos, os governantes, os comerciantes? Eu imagino que você encontre talvez mais semelhanças entre as experiências dos escravos nas áreas francesas e nas áreas portuguesas do que entre escravos e senhores numa mesma área.

Stuart Schwartz: É verdade. O primeiro ponto sobre as diferenças geográficas é importante. No Caribe temos realmente dois tipos de ilhas. Nas ilhas planas, de formação 
geológica sem vulcôes, os efeitos dos furacôes são diferentes das que têm montanhas. Mas há diferenças também na maneira como a sociedade podia responder esses fenômenos. Nas ilhas montanhosas houve sempre áreas não ocupadas por produção de produtos de exportação. Nestas, os escravos depois da escravidáo saíram dos engenhos ou das fazendas e foram constituir um tipo de campesinato. A Jamaica é um exemplo, ou ainda o Haiti. Mas, em ilhas como Barbados, onde isso não existe, os ex-escravos tinham que ficar como trabalhadores nas grandes propriedades porque não havia alternativa senão imigrar para outra ilha. Eram estas as diferenças geológicas que faziam a diferença.

Mas você tem razão, os escravos têm mais coisas em comum entre si, quando são de ilhas diferentes, do que os senhores e seus próprios escravos. E o livro trata muito de fazer essa diferenciaçáo entre camadas da população: escravos, senhores e pessoas livres que não eram senhores. Mas é preciso levar em conta que, nas ilhas do Caribe, o percentual de escravos era muito mais alto do que no Brasil. Em muitas das ilhas, no final do século XVIII, a população de escravos era de $85 \%$. Mesmo nas zonas açucareiras do Brasil não havia uma população táo concentrada de escravos. Nesse sentido, o Caribe náo tinha a mesma gama de atores no processo histórico.

O furacão tem consequências particulares. Como se sabe, todos os impérios tinham leis de exclusivos, que determinavam que a colônia só podia comercializar com a metrópole. Mas depois de passar um furacão, se as pessoas não tivessem o que comer, o governador de uma ilha francesa, por exemplo, iria para a ilha mais próxima, qualquer que fosse sua nacionalidade, negociar comida. O Caribe é uma zona clássica de contrabando e o furacão intensifica, portanto, esse processo. Intensifica o contrabando não só entre os habitantes, mas entre os governos. O governador espanhol sabia que era proibido comercializar com uma ilha francesa, mesmo assim ele podia mandar um barco com uma carta ao governador francês (ao superintendente de Martinica, por exemplo), dizendo que precisava de tantas arrobas de milho. Havia, assim, reaçôes políticas a esses fenômenos naturais que temos que levar em conta.

Também o furacão criava um sentido de comunidade em relação aos desastres. Às vezes, isso se dava entre a populaçáo daquele espaço, mas também entre inimigos nacionais, mas que, confrontados com a mesma força da natureza, se sentiam como numa mesma comunidade. Tenho uma bela carta de um governador de Terra Nova, Canadá, dirigida ao governador espanhol de Porto Rico, que já era seu conhecido. Com a chegada de um novo furacão, essa carta de simpatia foi enviada com dinheiro para ser distribuído para a populaçáo pobre da ilha, em finais do século XVIII. Também há o caso de um governador de Martinica que, depois de uma armada inglesa ser destruída por um furacáo nas águas da ilha, ele recupera as vítimas e, ao invés de torná-las prisioneiros de guerra, ele as devolve ao governador inglês dizendo que "diante da natureza todos somos irmáos". E isso se deu durante a guerra. Pelo visto, é interessante notar como o desastre natural tem esse tipo de influência política e social. 
José Augusto PÁdua: Em primeiro lugar, acho interessante registrar que temos no nosso instituto um laboratório de história ambiental. E a história ambiental que vem se desenvolvendo no Brasil das últimas décadas teve uma presença forte de Warren Dean.

\section{Stuart Schwartz: Outro brasilianista!}

José Augusto PÁdua: Sim. Você fez o prefácio do livro dele sobre a Mata Atlântica. ${ }^{15}$ Acho interessante ver que você trabalha agora com os furacóes e tem esse diálogo. A pergunta que eu quero fazer é mais teórica. Como trabalhar essas questóes de uma forma menos dualista? Há um dualismo na ideia da natureza que gera um impacto, um desastre, e na internalização desses fatos na vida econômica, social e cultural de uma sociedade. Acho que o que é interessante não é o furacáo, quando acontece, mas como a sua regularidade ou a sua presença constante afeta a agricultura, a economia, a política, o imaginário.

Stuart SchWartZ: Na historiografia do Caribe, francesa e inglesa, no século XVIII, há sempre a observação de um fatalismo. Um historiador francês, que conhecia bem a Martinica, escreve que a ideia é fazer riqueza e gastá-la rapidamente porque existe um fatalismo, porque se sabe que, num instante, tudo pode acabar. Ou seja, tudo pode ser tomado pelo furacão.

E eu pensei, como filho da história econômica, em medir o efeito, em longo prazo, dos furacóes na economia do Caribe. Mas o problema é o seguinte: chegando ao final do século XVIII, os grandes senhores de escravos perceberam que o furacáo era uma maneira de renovar a terra, que ele tinha efeitos positivos e, mesmo que a safra de um ou dois anos fosse perdida, em longo prazo era possível que as safras pudessem melhorar. Então, era muito difícil medir os efeitos negativos do furacáo porque, em longo termo, o resultado poderia ser benéfico para a agricultura. E tudo isso entrou na mentalidade do Caribe. Outro aspecto que sempre me preocupa - acho que também preocupa vocês que estão trabalhando com meio ambiente - é que é muito difícil evitar o erro clássico do determinismo geográfico, do determinismo ambiental, de considerar que, se uma zona tem terremoto, se tem determinado tipo de clima, tudo acontece de uma mesma maneira. Acho que todos nós que estamos tratando com o ambiente temos o desafio, sempre presente, de evitar esse tipo de determinismo.

Quando eu era estudante meu pai me comprou o livro de Toynbee, $O$ estudo da história, ${ }^{16}$ que traz a interpretação de que as civilizaçóes nunca estão nas áreas do Ártico ou da Antártica porque o clima é táo duro que a luta pela vida toma toda a energia do homem. Então,

\footnotetext{
${ }^{15}$ DEAN, Warren. A ferro e fogo: a história e a devastação da Mata Atlântica brasileira. São Paulo: Companhia das Letras, 1996.

${ }^{16}$ TOYNBEE, Arnold J. Um estudo da história. São Paulo: Martins Fontes, 1987.
} 
a civilização é impossível no extremo norte ou no extremo sul. E também, do outro lado, na Polinésia, onde se colhe banana da árvore, onde não há desafios, ou seja, não se precisa de civilização. A civilização só se encontra em meio propício, só se encontra na Inglaterra, exatamente na "zona da civilização". Toynbee dizia que temos na natureza uma fábula de Goldilocks (Cachinhos dourados) — a história de uma menina que entra numa casa onde há três ursos e três camas, uma demasiado dura, outra demasiado mole e a terceira muito boa. Essa interpretação determinista de Toynbee em relação ao ambiente é o que temos que evitar! Mas isso é difícil porque a realidade do Caribe inclui os terremotos e, especialmente, os furacôes: há furacóes todos os anos, se não nessa ilha, em outra, e entre seis e vinte a cada ano, em algumas ilhas. Não há evento da história do Caribe que não aconteça depois de um furacão. Não há eleição, guerra, golpe, nada que aconteça sem a presença — antes ou depois — de um furacão. Tenho que evitar, inclusive, a tendência de dizer, por exemplo, "subiu ao poder por causa de tal furacão". É preciso muito cuidado, mas ao mesmo tempo é preciso reconhecer a influência do ambiente na política, na sociedade e em todos os aspectos da vida. Esse é, de fato, um desafio muito grande para todos os historiadores do ambiente.

Andrea Casa Nova Maia: Eu queria retomar o tema da catástrofe no âmbito das redes de solidariedade. Queria que você falasse um pouco das redes de solidariedade entre as comunidades atingidas pelos furacóes. Você falou também de método — falou da longa duração, citou Braudel —, mas queria que você falasse mais sobre as suas fontes. Que fontes foram utilizadas para estudar esses furacóes numa longa duração?

Stuart Schwartz: O meu livro é exatamente sobre isso: redes sociais. Por exemplo, na Jamaica, em 1780, passou o chamado Grande Furacão, que matou 22 mil pessoas. $\mathrm{O}$ Caribe naquela época estava cheio de barcos franceses e ingleses por causa da Guerra de Independência dos Estados Unidos. Havia muitos soldados, marinheiros e barcos na região, e esse furacão enorme que passou pelas Antilhas matou muita, muita gente. Depois disso, o governo britânico, pela primeira vez, mandou dinheiro para a Jamaica e para Barbados para ajudar as vítimas do furacão e uma verdadeira luta se iniciou por conta desse auxílio. Os grandes fazendeiros diziam que a economia era o suporte do império e os escravos estavam morrendo de fome. Esse grupo achava que o auxílio deveria lhes ser pago para que pudessem dar comida aos escravos. Mas os comerciantes não concordavam, pois haviam perdido seus barcos, com caixas de açúcar, e defendiam que eles, sim, deveriam receber a ajuda. Por sua vez, os artesãos, a população de cor, livre, esses não receberam nada. Então, houve em todas essas ilhas um momento de luta que começou no momento em que o auxílio devia ser distribuído. Como distribuí-lo? Dar aos grandes fazendeiros, dar aos comerciantes ou dar diretamente aos pobres? O governo tinha que se confrontar com isso, e disputas como essa aconteceram a cada vez que passou um furacão. 
E isso pode ser o passo para a segunda pergunta: no século XVIII, cada desastre levava o governador a fazer apelos de ajuda. Aí temos um primeiro tipo de documentaçáo. No século XIX, há uma correspondência muito boa, em Cuba e Porto Rico, de engenheiros militares espanhóis que eram mandados para esses lugares e que, no processo de reconstrução das pontes e dos caminhos arruinados pelo furacão, fizeram observaçôes políticas e disseram que, se a Coroa espanhola não fizesse melhorias nesses países, perderia as colônias. Eles percebiam que o império não dava benefícios para a população dessas colônias e elas não podiam reagir frente aos desastres naturais.

Então, durante os desastres naturais se revelava uma imagem da sociedade que evidenciava exatamente onde estavam as divisôes, os interesses e quem era a oposição ao governo. $\mathrm{E}$ esses engenheiros militares espanhóis, muito inteligentes, jovens, no início de suas carreiras, escreveram com uma percepção apurada sobre isso.

Houve um grande furacão em Porto Rico, em 1867 — furacão de San Narciso, pois o furacão leva, em geral, o nome do santo do dia em que ele passa -, no momento de um primeiro movimento de independência. Betances, que era uma espécie de Tiradentes porto-riquenho, suspendeu a rebelião por causa do furacáo que fez com que fosse impossível montar resistência ao governo naquele momento. Como visto, há momentos em que eles são muito importantes.

Mas a documentação é sempre produzida porque há um efeito dos furacôes na sociedade em geral. Os furacóes estão citados até nas crônicas dos conventos. Na documentação hispânica, há também as rogativas, que são procissóes feitas pela Igreja para pedir proteção contra a chuva ou contra tormentas. Através de atas capitulares podemos saber exatamente quando aconteceu uma rogativa. É o mesmo tipo de documentação que os franceses utilizaram para fazer uma história do clima da França, segundo a colheita do vinho. Acho que, talvez, essa seja uma fonte náo explorada no Brasil para se fazer uma história do clima.

Roberto Guedes: Você expôs os impactos demográficos de um furacão e deu um exemplo de mortalidade elevadíssima na Jamaica, 22 mil pessoas. Isso equivale à população do Rio de Janeiro, mais ou menos, em 1820. Eu queria saber, segundo as suas pesquisas, qual o impacto disso no próprio tráfico de escravos nessas áreas? Ainda que haja uma variação entre os locais como Barbados, São Domingos etc., como isso impactou o tráfico, o fluxo econômico, o fluxo de pessoas? Como você explicou, essas são áreas com um desequilíbrio demográfico entre homens livres e escravos que não há no Brasil e em outras áreas escravistas da América Latina. Ou seja, há uma desproporção muito grande no Caribe. Como isso estimulou o próprio movimento do tráfico, sendo o Caribe a área de maior recepçáo dos escravos no século XVIII? Como esses furacóes estavam relacionados com a escravidão e o tráfico? 
Stuart Schwartz: A temporada de furacóes era conhecida e os ingleses evitavam o comércio durante esse período. Os espanhóis aprenderam também, e todo o seu sistema de frotas funcionava de acordo com a temporada de furacóes. Quanto ao número de escravos que chegaram aos diferentes lugares, não sei dizer. Sei que houve temporadas em que não chegavam escravos às Antilhas por ser temporada de furacôes. Há até um tipo de fonte que não explorei - e sei que essa é uma falha do meu trabalho — que é a documentação das companhias de seguro. Elas sabiam muito bem sobre estes riscos de enchente, de furacão etc. A documentação das grandes companhias de seguro da Inglaterra - todos os barcos de comércio de escravos tinham seguro - é outro tipo de fonte que poderia ser explorada para a história ambiental.

Sobre o número de escravos não tenho resposta, mas sei que o comércio era concentrado durante os meses em que não havia catástrofe.

Roberto Guedes: É que no pós-catástrofe há epidemias, doenças...

Stuart Schwartz: Sim, depois das catástrofes isso era sempre um problema. No Caribe, o problema era a malária e a febre amarela. Muito difícil. Em toda a história do Caribe o maior "império" era o dos mosquitos, como diz o livro recente de John McNeill, Mosquito empires $\left[O\right.$ império dos mosquitos]. ${ }^{17}$ Os espanhóis sabiam que não era necessário organizar uma grande armada para atacar os ingleses quando estes atacavam um porto espanhol, porque os defensores só tinham que esperar seis semanas para que os ingleses morressem pelos mosquitos. Então, toda a defesa das fortalezas espanholas era uma proteção defensiva natural. Não era necessário atacar, só esperar pelos mosquitos que matariam os recém-chegados. O furacão é só um dos elementos desse ambiente tão importante na definição da região do Caribe.

LiSE SEDREZ: Na sua discussão sobre essa história ambiental do Caribe você vê o desastre como um processo, não como um evento. Existe entâo uma história prévia, de preparação ou de negligência, que torna algumas áreas mais vulneráveis que outras ao próprio evento da catástrofe, e finalmente o momento pós-catástrofe, ou seja, a reação das comunidades e dos governos.

STUART SchwartZ: Sim, meu ponto de partida é que não há desastre natural. Um furacão que passa sobre uma ilha desabitada não é um desastre, é simplesmente um fenômeno da natureza. O que faz o desastre é o que os humanos fazem, antes e depois do furacáo. Muitas vezes, na falta de preparação, se faz o desastre. Ou ainda, em casos como o do furacáo Ka-

\footnotetext{
${ }^{17}$ MCNEILL, John. Mosquito empires: ecology and war in the Greater Caribbean 1620-1914. Cambridge: Cambridge University Press, 2010.
} 
trina, nos Estados Unidos, aquilo que o governo não fez após o furacão é que ocasionou a catástrofe. Mas o fenômeno em si não é uma catástrofe, o que se faz é o que faz a catástrofe. Esse é meu ponto de partida para a interpretação.

Andrea Daher: Pergunto, para finalizar: o que virá "depois do dilúvio"?

Stuart Schwartz: No próximo projeto, eu volto ao Brasil. Desde o início, desde quando comecei a estudar o Brasil, o meu objetivo era fazer uma história do Brasil filipino e do período depois da Restauração. No início desse período, os impérios espanhol e português eram as grandes potências do mundo e da Europa. E no final desse período eram potências de segundo ou terceiro grau. $\mathrm{O}$ que aconteceu? E por que o Brasil era uma peça-chave nessa história? Estive recolhendo materiais, por muitos anos. Tenho um contrato com Jean-Frédéric Schaub, historiador francês que trabalhou muito com Portugal, para fazermos um livro em conjunto. Por isso, estou voltando ao Brasil para estudar o período filipino. Esse vai ser o próximo projeto.

Andrea DAHer: Estaremos prontos para recebê-lo. 